Artículo

\title{
Polifenoles de diferentes fuentes vegetales y su efecto in vitro contra patógenos del garbanzo
}

\author{
Ivón Alejandra Rosas Jauregui ${ }^{1,2}$ \\ Francisco Daniel Hernández Castillo ${ }^{1 \S}$ \\ Lissethe Palomo Ligas ${ }^{3}$ \\ Saira Roció Martínez Alemán ${ }^{3}$ \\ Juan Alberto Ascacio Valdés ${ }^{3}$ \\ Raúl Rodríguez Herrera ${ }^{3}$
}

${ }^{1}$ Universidad Autónoma Agraria Antonio Narro. Calzada Antonio Narro núm. 1923, Col. Buenavista Saltillo, Coahuila. CP. 25315. Tel. 844 4110327. ${ }^{2}$ Campo Experimental Norman E. Borlaug-INIFAP. Calle Dr. Norman E. Borlaug km 12, Cd. Obregón, Sonora. CP. 85000. (ivonn1590@ hotmail.com). ${ }^{3}$ Departamento de Facultad de Ciencias Químicas-Universidad Autónoma de Coahuila. Ing. Cárdenas Valdez s/n, Col. República, Saltillo, Coahuila. CP. 25280. Tel. 844 4161238. (b-clic@ hotmail.com; saira.mtz.aleman@hotmail.com; alberto_ascaciovaldes@uadc.edu.mx; rrh961@hotmail.com).

${ }^{\S}$ Autor para correspondencia: fdanielhc@ hotmail.com.

\section{Resumen}

La producción del garbanzo (Cicer arietinum L.) constantemente está comprometida por un complejo de patógenos que ocasionan la marchitez y pudrición de raíz (MPR). Algunas de las estrategias empleadas para el manejo de esta enfermedad son el uso de variedades resistentes, rotación de cultivos, solarización, retiro de socas y uso de semillas libre de patógenos o tratadas con fungicidas, aunque los resultados han sido limitados o poco satisfactorios, en los últimos años, el control biológico y los productos orgánicos ha cobrado mayor importancia. En el presente trabajo se obtuvieron polifenoles de extractos etanólicos mediante la técnica asistida de ultrasonidomicroondas de las especies vegetales: hoja de trueno (L. lucidum), granos de sorgo (S. bicolor) y hojas de moringa (M. oleífera). Se les realizó el correspondiente análisis cualitativo mediante HPLC masas y se determinó el efecto antifúngico de cada grupo de polifenoles extracto sobre tres hongos fitopatógenos que conforman el complejo de la marchitez y pudrición de raíz, por medio de la técnica de dilución en placa y medio envenenado. Se determinó el porcentaje de inhibición y la concentración inhibitoria $\left(\mathrm{CI}_{50}\right)$. Los resultados indican que los polifenoles tienen elevada efectividad biológica sobre el hongo Macrophomina y Fusarium solani, la actividad para Fusarium oxysporum f. sp. ciceris dependió de los polifenoles de cada especie vegetal; polifenoles de $L$. lucidum con una concentración de 491.99 ppm. Adicionalmente se comprobó que todos los grupos de polifenoles tenían en su composición química algunos compuestos de reconocida actividad microbiana como lo son: flavonas, antocianinas, catequinas y alquifenoles, entre otros.

Palabras clave: Fusarium, Macrophomina, polifenoles.

Recibido: agosto de 2021

Aceptado: octubre de 2021 


\section{Introducción}

El garbanzo (Cicer arietinum L.), ocupa el segundo lugar a nivel mundial entre las leguminosas de grano seco, solo después del frijol (Phaseolus vulgaris L.) (Morales y Durón, 2004). En México, en el año agrícola 2016, la superficie dedicada a la producción de este cultivo fue de 66096 ha sembradas, con una producción de 116076 t; Sinaloa y Sonora fueron los principales estados productores al aportar 45 y 30\% de la producción nacional, respectivamente (SIAP, 2017). Entre las enfermedades que limitan la producción de garbanzo está la fusariosis vascular, es causada por Fusarium oxysporum f. sp. ciceris (FOC). En España se reportan pérdidas de la producción de 10 a 15\% y en otros países entre 10 y 90\% (Landa et al., 2006; Sharma y Muehlbauer, 2007).

Sin embargo, la marchitez por Fusarium puede causar pérdidas de $100 \%$, cuando el cultivo está expuesto a condiciones adversas como el calor o por estrés de agua durante la fase reproductiva y el desarrollo de la cápsula (Landa et al., 2006). Por mucho tiempo la 'rabia' causada por Didymella rabiei (Kovatsch.) se consideró la enfermedad más importante del garbanzo en España (Arx Navas et al., 1998). Sin embargo, otros estudios indican que se presenta ocasionalmente, mientras que la 'seca' o 'fusariosis' ha aumentado. Se sugiere que la fusariosis pudiera incluir un complejo de patógenos similar a la marchitez y pudrición de raíz (MPR), que reduce la producción de semillas de garbanzo, varios hongos se han reportado como los agentes del complejo MPR, entre los cuales se mencionan a Fusarium, Rhizoctonia, Macrophomina y Sclerotium (Padilla et al., 2008).

Algunas de las estrategias empleadas para el manejo de esta enfermedad son el uso de variedades resistentes, rotación de cultivos, solarización, el retiro de socas y uso de semillas libre de patógenos o tratadas con fungicidas, aunque los resultados han sido limitados o poco satisfactorios (Paredes et al., 2009). El control químico es el método más usado en el control de enfermedades que ocasionan las especies de Fusarium; sin embargo, en los últimos años el control biológico ha cobrado mayor importancia (Basco et al., 2017). Diversas investigaciones se centran en estudios sobre la formulación de productos naturales con algún tipo de actividad biológica sobre hongos fitopatógenos con una eficacia y una acción cada vez mayor y más rápida, lo que está generando que estas prácticas sean más eficaces en un amplio rango de condiciones ambientales, de especies de plagas y de sistemas de cultivos (Gakuya et al., 2013).

Se reconoce la importancia de las especies vegetales y sus derivados (extractos, aceites esenciales, decocciones, metabolitos secundarios) en la protección de cultivos bajo el manejo integrado de plagas y enfermedades (MIPE) (Sparks et al., 2017). Por lo anterior, el objetivo del presente trabajo fue evaluar in vitro, la efectividad biológica de polifenoles de trueno, moringa y sorgo obtenidos mediante extractos etanólicos contra hongos asociados a la marchitez y pudrición del garbanzo.

\section{Materiales y métodos}

\section{Obtención de material vegetal}

Hojas frescas de trueno (Ligustrum lucidum) fueron recolectadas en la Universidad Autónoma Agraria Antonio Narro (3532 ${ }^{\circ}$ latitud norte, $101.0332^{\circ}$ longitud oeste: $1786 \mathrm{msnm}$ ), las hojas de Moringa (Moringa oleifera) fueron obtenidas en Ciudad Obregón, Sonora (27 $22^{\prime}$ '04' latitud norte, $109^{\circ}$ 55' 28' longitud oeste y $37 \mathrm{msnm}$ ), los granos de Sorgo (Sorghum bicolor) se 
obtuvieron de la variedad BRS-72 (con alto contenido de taninos) en la Ciudad de Tecomán, Colima (18 $54^{\prime}$ '51' latitud norte $103^{\circ} 52^{\prime} 30^{\prime \prime}$ longitud oeste y $33 \mathrm{msnm}$.) El material vegetal fue trasladado a los laboratorios del Departamento de Alimentos de la Facultad de Ciencias Químicas, donde se seleccionaron hojas y granos en base al tamaño y sin presencia de daño, para ser sometidas a deshidratación por un periodo de dos semanas a temperatura ambiente, posteriormente se pulverizaron y tamizaron (RO-TAP; TYLER), utilizando un tamiz de $150 \mu$.

\section{Extracción asistida mediante ultrasonido-microondas}

El material vegetal pulverizado se colocó en el reactor con las cantidades obtenidas de las relaciones que se muestran en la (Cuadro 1) y se introdujo este reactor en el equipo de ultrasonido y microondas (Nanjing ATPIO Instrumens Manufacture Co., Ltd Company, China) bajo las siguientes condiciones: Ultrasonic (VS): Power Radio 20, Ultrasonic on Relay 10, Ultrasonic off Relay 3, Amplitud off Relay 25 y Set Time 20. Microwave (MV): Power Radio 800, Display power 0, Set Temp $70{ }^{\circ} \mathrm{C}$ y Holding Time 5. Después del proceso de ultrasonido y microondas las muestras fueron almacenadas en un ultracongelador a una temperatura de $-70{ }^{\circ} \mathrm{C}$.

Cuadro 1. Descripción de las relaciones de la extracción asistida mediante ultrasonidomicroondas.

\begin{tabular}{cccc}
\hline Núm. & $(\%)$ etanol & ml:1 g de muestra & Relación \\
\hline 1. L. lucidum & $70 \%$ (alto) & 16 (alto) & Alto x alto \\
2. S. bicolor & $70 \%$ (alto) & 8 (bajo) & Alto x bajo \\
3. M. oleífera & $70 \%$ (alto) & 16 (alto) & Alto x alto \\
\hline
\end{tabular}

\section{Cromatografía de columna con amberita}

La cromatografía por columna se realizó con el relleno cromatográfico de amberlita XAD- 16N. Esto incluye la activación de la amberlita con el metanol, el empaquetado de la columna, la filtración de los extractos, secado de los extractos y el desempaquetado de la columna cromatografía De Asmundis et al. (2011).

\section{Recuperación de extracto seco}

Una vez obtenida la fracción etanólica, ésta se repartió en recipientes de vidrio y se secaron en estufa a $60{ }^{\circ} \mathrm{C}$, sin exponer a la luz por 24 a $48 \mathrm{~h}$. Finalmente se colectó el extracto seco en forma de polvo en un frasco ámbar a temperatura ambiente para su posterior análisis.

\section{Caracterización de fitoquímicos presentes en los extractos vegetales mediante cromatografía de líquidos de fase inversa (HPLC masas)}

El análisis por cromatografía líquida de alta resolución en fase inversa se realizó siguiendo la metodología de Ascacio et al. (2016), que consiste en utilizar un sistema de HPLC Varian que incluye un inyector automático (Varian ProStar 410, EE. UU.), una bomba ternaria (Varian ProStar 2310, EE. UU.) y un decantor PDA (Varian ProStar 330, EE. UU.). También se utilizó un espectrómetro de masas con trampa de iones de cromatógrafo de líquidos (Varian 500-MS IT Mass Spectrometer, EE. UU.) equipado con una fuente de iones por electropulverización. 
Se inyectaron muestras $(5 \mu \mathrm{l})$ en una columna Denali C18 (150 mm x $2.1 \mathrm{~mm}, 3 \mu \mathrm{m}$, Grace, EE. UU.). La temperatura del horno se mantuvo a $30{ }^{\circ} \mathrm{C}$. Los eluyentes fueron ácido fórmico $(0.2 \%$, V/V; disolvente A) y acetontrilo (disolvente B). Se aplicó el siguiente gradiente: inicial, 3\% B; 05 min, 9\% B lineal; 5-15 min, 16\% B lineal; 15-45 min, 50\% B lineal. Después la columna se lavó

y se reacondicionó, el caudal se mantuvo a $0.2 \mathrm{ml} \mathrm{min}^{-1}$ y la elución se controló a 245, 280, 320 y $550 \mathrm{~nm}$. Se inyectó todo el efluente $\left(0.2 \mathrm{ml} \mathrm{min}^{-1}\right)$ en la fuente del espectrómetro de masas, sin dividir.

Todos los experimentos de EM se llevaron a cabo en modo negativo [M-H] ${ }^{-1}$. Se utilizó nitrógeno como gas nebulizador y helio como gas amortiguador. Los parámetros de la fuente de iones fueron: voltaje de pulverización $5 \mathrm{kV}$ y voltaje capilar y temperatura fueron $90 \mathrm{~V}$ y $350{ }^{\circ} \mathrm{C}$, respectivamente. Los datos se recopilaron y procesaron utilizando el Software MS Workstation (V 6.9). Las muestras se analizaron en primer lugar en modo de barrido completo adquiridas en el rango m/z 50-2000.

\section{Obtención e identificación de hongos}

Las cepas empleadas en los bioensayos fueron aisladas de plantas de garbanzo con síntomas de marchitamiento y amarillamiento, localizadas en el Valle del Yaqui a una latitud $27^{\circ} 29.185^{\prime}$ longitud $-109^{\circ} 56.45^{\prime}$ oeste. Pequeños trozos de raíces de plantas con síntomas de la enfermedad se desinfectaron con una solución de cloro al 3\% y fueron enjuagadas con agua destilada estéril. Se colocaron en cajas Petri con medio de cultivo papa-dextrosa-agar (PDA) y se incubaron por tres días a $28{ }^{\circ} \mathrm{C}$. Finalmente el aislamiento se realizó mediante punta de hifa.

\section{Identificación molecular mediante PCR y amplificación aleatoria de polimorfismo del ADN (RAPD)}

Para la extracción del ADN de cada uno de los aislados de los hongos, se utilizaron cultivos de micelio puro crecidos en $50 \mathrm{ml}$ de caldo papa dextrosa, incubados a $25{ }^{\circ} \mathrm{C}$ durante ocho días. Al término de este tiempo, los cultivos se centrifugaron a $10000 \mathrm{rpm}$ por $10 \mathrm{~min}$ a temperatura ambiente, se descartó el sobrenadante y la pastilla celular se lavó con PBS. La lisis de la muestra se realizó con 3 ciclos de congelamiento-calentamiento $\left(-80^{\circ} \mathrm{C}, 75^{\circ} \mathrm{C}\right)$ durante $15 \mathrm{~min}$, maceración e incubación por $15 \mathrm{~min}$ en buffer TES (Tris-HCl $50 \mathrm{Mm}$ pH 7.5, EDTA 20 Mm, SDS 1\%).

El ADN total del micelio se obtuvo por purificación con el método de fenol-cloroformo-alcohol isoamilico (25:24:1) y se precipitó con etanol. La determinación de la concentración y calidad del material genético se realizó por espectrofotometría (EPOCH; BioTek). Para la identificación de $M$. phaseolina y $F$. solani se utilizaron oligonucleótidos específicos que amplifican para una región conservada adyacente al gen 5.8 S y el gen TEF-1 $\alpha$, respectivamente (Babu, 2007; Arif, 2012).

La amplificación se realizó por PCR con la enzima Taq ADN polimerasa (qARTA Bio) y 100 $\mathrm{ng} / \mu \mathrm{L}$ de material genético, utilizando las condiciones de amplificación descritas por estos autores: 25 ciclos de desnaturalización a $95{ }^{\circ} \mathrm{C}$ por $30 \mathrm{~s}$, alineamiento a $56{ }^{\circ} \mathrm{C}$ por $1 \mathrm{~min}$, extensión a $72{ }^{\circ} \mathrm{C}$ por $2 \mathrm{~min}$, y un paso de extensión final a $72{ }^{\circ} \mathrm{C}$ por $10 \mathrm{~min}$ para $\mathrm{M}$. phaseolina y 40 ciclos de desnaturalización a $94{ }^{\circ} \mathrm{C}$ por $1 \mathrm{~min}$, alineamiento a $58^{\circ} \mathrm{C}$ por $1 \mathrm{~min}$, extensión a $72{ }^{\circ} \mathrm{C}$ por 2 min para F. solani. 
Aparte, la identificación de las razas patogénicas de Fusarium oxysporum f. sp. ciceris se realizó mediante la técnica de amplificación aleatoria de polimorfismo del ADN (RAPD) utilizando los marcadores OPF y OPI, en donde se distinguen las razas mediante la ausencia o presencia de patrones electroforéticos con la misma movilidad, las condiciones de amplificación fueron las siguientes, desnaturalización a $94^{\circ} \mathrm{C}$ por $4 \mathrm{~min}$, seguida de 30 ciclos de $94{ }^{\circ} \mathrm{C}$ por $1 \mathrm{~min}$, alineamiento a $40{ }^{\circ} \mathrm{C}$ por $1 \mathrm{~min}$, extensión a $72{ }^{\circ} \mathrm{C}$ por $3 \mathrm{~min}$ y extensión final a $72{ }^{\circ} \mathrm{C}$ por 7 min (Jiménez-Gasco, 2001). Los productos amplificados se separaron por electroforesis en geles de agarosa (Ultra Pure Agarose Invitrogen) al 1\%, en amortiguador TAE. Los geles fueron teñidos con nucleic acid gel stain (Invitrogen). Las bandas correspondientes de los productos amplificados fueron observadas con luz UV. Se capturaron las imágenes con cámara digital (UVP; GDS-8000).

\section{Actividad antifúngica de los extractos vegetales contra $M$. phaseolina por el método de medio envenenado}

Se determinó la actividad antifúngica por el método de medio envenenado propuesto por Jasso de Rodríguez et al. (2011), los tratamientos de los polifenoles obtenidos de: Ligustrum lucidum, Moringa oleifera y Sorghum bicolor fueron en concentraciones de $50 \mathrm{mg} \mathrm{L}^{-1}, 100 \mathrm{mg} \mathrm{L}^{-1}, 200 \mathrm{mg}$ $\mathrm{L}^{-1}, 300 \mathrm{mg} \mathrm{L}^{-1}, 400 \mathrm{mg} \mathrm{L}^{-1}, 500 \mathrm{mg} \mathrm{L}^{-1}$ y $600 \mathrm{mg} \mathrm{L}^{-1}$ : con cuatro repeticiones por tratamiento. Primero se determinó la concentración y el volumen para cada uno de los polifenoles y se añadió a un matraz con la cantidad requerida de PDA estéril. Posteriormente se colocaron discos de 0.4 $\mathrm{cm}$ de diámetro con micelio activo del hongo de siete días de crecimiento, finalmente se incubaron a $28 \pm 2{ }^{\circ} \mathrm{C}$ hasta que el testigo absoluto lleno la caja por completo. Se determinó el porcentaje de inhibición mediante la siguiente formula: porcentaje de inhibición= (DC-DT/DC)*100. Donde DC es el diámetro del tratamiento control, y DT es el diámetro de las diferentes concentraciones.

\section{Actividad antifúngica de los extractos vegetales contra $F$. oxysporum f. sp. ciceris y $F$. solani por el método de microdilución en placa}

Se utilizó el método de microdilución en placa adaptada de las técnicas propuestas por Masoko et al. (2005); Gabrielson et al. (2002). Para esto se usaron placas de poliestireno de 96 pozos. El procedimiento inicio colocando $100 \mu \mathrm{l}$ de medio líquido sabouraud en cada pozo de la placa, posteriormente cada grupo de polifenoles se preparó a una concentración de $2000 \mathrm{mg} \mathrm{L}^{-1}$ utilizando etanol como solvente, posteriormente se colocaron $100 \mu \mathrm{l}$ de los polifenoles preparados a $2000 \mathrm{mg} \mathrm{L}^{-1}$ en la columna cuatro, se mezclaron y se volvió a tomar $100 \mu \mathrm{l}$ y se transfirieron a la siguiente columna y así sucesivamente realizando diluciones seriadas al 50\% hasta la columna 12, teniendo como resultado concentraciones de $1000 \mathrm{mg} \mathrm{L}^{-1}, 500 \mathrm{mg} \mathrm{L}^{-1}, 250$ $\mathrm{mg} \mathrm{L}^{-1}, 125 \mathrm{mg} \mathrm{L}^{-1}, 62.5 \mathrm{mg} \mathrm{L}^{-1}, 31.2 \mathrm{mg} \mathrm{L}^{-1}, 15.6 \mathrm{mg} \mathrm{L}^{-1}, 7.8 \mathrm{mg} \mathrm{L}^{-1}$ y $3.9 \mathrm{mg} \mathrm{L}^{-1}$, el siguiente paso fue agregar $40 \mu \mathrm{l}$ de 2,3,5- cloruro de trifeniltetrazolio como revelador de crecimiento a todos los pozos; finalmente a partir de la columna dos se colocó una solución de esporas de $F$. oxysporum y $F$. solani a una concentración de $1 \times 10^{8}$.

Cada placa se consideró una repetición, y se realizaron tres repeticiones por tratamiento, se incubaron a $28{ }^{\circ} \mathrm{C}$ por $48 \mathrm{~h}$ y finalmente se realizó una lectura de absorbancia a $490 \mathrm{~nm}$ en espectrofotómetro. Se consideró crecimiento positivo del hongo a los tratamientos donde el pozo presentó un color rosado y negativo a los que no presentaron ningún color, además de sus respectivos valores de absorbancia. El porcentaje de inhibición se calculó adaptando la fórmula propuesta por Moreno-Limón et al. (2011), considerando que el porcentaje de inhibición es el 
inverso del porcentaje de crecimiento. Porcentaje de crecimiento $=(A-B) / C(100)$. Donde: $A=$ absorbancia de tratamiento, $\mathrm{B}=$ absorbancia del testigo negativo, $\mathrm{C}=$ absorbancia del testigo positivo. Porcentaje de inhibición= 100 - porcentaje de crecimiento.

\section{Análisis estadístico}

Los experimentos fueron establecidos bajo un diseño de bloques completamente al azar con tres repeticiones. Se realizó un análisis Probit para determinar la concentración inhibitoria $\left(\mathrm{CI}_{50}\right)$ de cada grupo de polifenoles, posteriormente se realizó un análisis de varianza con las concentraciones inhibitorias $\left(\mathrm{CI}_{50}\right)$ y se compararon las medias de los tratamientos utilizando la prueba de rango múltiple de Tukey $(\alpha<0.05)$.

\section{Resultados y discusión}

Fitoquímicos presentes en los extractos vegetales, caracterizados mediante cromatografía de líquidos de fase inversa (HPLC)

Dentro de los resultados obtenidos por HPLC se pueden observar con mayor frecuencia la presencia de compuestos de la familia de flavonas, ácido hidroxicinámico y antocianinas (Cuadro 2).

Cuadro 2. Grupos de polifenoles detectados en los extractos de tres fuentes vegetales mediante la tecnología de cromatografía líquida de alta resolución acoplada a la espectrometría de masas (HPLC-MS).

\begin{tabular}{|c|c|c|c|c|}
\hline $\begin{array}{l}\text { Extracto } \\
\text { etanólico }\end{array}$ & Masa & $\begin{array}{l}\text { Tiempo de } \\
\text { retención }\end{array}$ & Compuesto & Familia \\
\hline \multirow{10}{*}{$\begin{array}{c}\text { Sorghum } \\
\text { bicolor 1:8 } \\
\text { etanol } 70 \%\end{array}$} & 341 & 2.856 & 3,4-DHPEA-EA & Tirosol \\
\hline & 340.9 & 3.652 & Glucosa Caffey & $\begin{array}{c}\text { Ácido } \\
\text { Hidroxicinámico }\end{array}$ \\
\hline & 304.7 & 9.431 & (+)-Galocatequina & Catequina \\
\hline & 304.8 & 23.776 & (-)-Epigalocatequina & Catequina \\
\hline & 252.9 & 26.878 & 7,4'-Dihidroxiflavona & Flavonas \\
\hline & 268.8 & 44.509 & 7,3',4'-Trihidroxiflavona & Flavonas \\
\hline & 564.1 & 54.302 & Pelargonidin 3-O-sambubioside & Antocianinas \\
\hline & 540.1 & 55.293 & Oleuropeína (posibilidad) & Tirosol \\
\hline & 566.1 & 55.731 & Floretina 2'-O-xilosil-glucosido & Dihidrocalcones \\
\hline & 325 & 56.896 & Glucosa p-Coumaroil & $\begin{array}{c}\text { Ácido } \\
\text { Hidroxicinámico }\end{array}$ \\
\hline \multirow{2}{*}{$\begin{array}{c}\text { Moringa } \\
\text { oleifera 1:16 } \\
\text { etanol } 70 \%\end{array}$} & 304.2 & 18.67 & Ácido 1-cafeoilquínico & Ácidos \\
\hline & 304.1 & 19.22 & Ácido 3-cafeoilquínico & $\begin{array}{c}\text { Ácidos } \\
\text { Hidroxicinámicos }\end{array}$ \\
\hline
\end{tabular}




\begin{tabular}{|c|c|c|c|c|}
\hline $\begin{array}{l}\text { Extracto } \\
\text { etanólico }\end{array}$ & Masa & $\begin{array}{l}\text { Tiempo de } \\
\text { retención }\end{array}$ & Compuesto & Familia \\
\hline \multirow{14}{*}{$\begin{array}{l}\text { Ligustrum } \\
\text { lucidum 1:16 } \\
\text { etanol } 70 \%\end{array}$} & 341 & 2.28 & Ácido tartárico p-coumaroil & Ácidos \\
\hline & & & & Hidroxicinámicos \\
\hline & 564.2 & 25.48 & Quercetina 3-O-galactosida & Ácidos \\
\hline & & & & Hidroxicinámicos \\
\hline & 310 & 32.82 & Quercetina 3-O-glucosido & Flavonol \\
\hline & 310 & 32.82 & Quercetina 4'-O-glucosida & Flavonol \\
\hline & 755 & 35.29 & $\begin{array}{c}\text { Peonidina 3-O-(6"-acetil- } \\
\text { galactosida) }\end{array}$ & Flavonol \\
\hline & 755 & 36.5 & $\begin{array}{c}\text { Peonidina } 3-\mathrm{O}-(6 " \text {-acetil- } \\
\text { glucosida })\end{array}$ & Antocianinas \\
\hline & 252.8 & 28.43 & Delfinidina 3-O-galactosida & Antocianinas \\
\hline & 540.1 & 51.35 & Bisdemetoxicurcumina & Curcuminoides \\
\hline & 592.8 & 30.55 & Apigenin 6,8-di-C-glucoside & Flavonas \\
\hline & 310.9 & 32.95 & Ácido Cefeoil tartárico & $\begin{array}{l}\text { Ácidos } \\
\text { Hidroxicinámicos }\end{array}$ \\
\hline & 755 & 34.67 & $\begin{array}{l}\text { Quercetina 3-O-ramnosil-ramnosil- } \\
\text { glucósido }\end{array}$ & Flavonas \\
\hline & 346.9 & 39.28 & 5-Heptadecilresorcinol & Alquifenoles \\
\hline
\end{tabular}

\section{Identificación y caracterización molecular de los aislados de hongos fitopatógenos}

La cepa de Macrophomina desarrollo colonias con las características de crecimiento micelial denso, de aspecto velloso, al inicio de color gris oscuro y posteriormente se tornó de color negro. La colonia desarrollo microesclerocios, estas características fueron similares a las de M. phaseolina Santos-Mier et al. (2015). Para el aislado fúngico analizado por PCR, se logró la amplificación de fragmentos de un tamaño de $350 \mathrm{pb}$ esto confirma que la cepa pertenece a la especie de $M$. phaseolina, dado que los indicadores MpKF1 y MpKR1son específicos para esta especie de hongo.

De acuerdo con Babu et al. (2007) las secuencias de ADN obtenidas con los iniciadores específicos MpKFI y MpKRI pueden ser utilizadas para identificar de forma rápida, selectiva y específica el hongo M. phaseolina. De manera similar, Zhang et al. (2011); Sánchez et al. (2013) usaron iniciadores específicos MpKFI y MpKRI para identificación y detección de aislados de $M$. phaseolina en fresa y frijol mungo (Vigna radiata L.), respectivamente (Figura 1a). Para la identificación y discriminación de $F$. solani se usó el set de primers TEFFs4, para ampliar el gen TEF-1 $\alpha$, mostrando un producto de 658 pb (Figura 1b) como lo reportó Arif et al. (2012).

Finalmente, para la identificación de las razas patogénicas $0,1 \mathrm{~B} / \mathrm{C}, 5$ y 6 de Fusarium oxysporum f. sp. ciceris por la técnica de RAPD se utilizaron siete oligonucleótidos específicos denominados OPF y OPI (Jiménez-Gasco, 2001). Se examinaron todas las muestras aisladas y se evalúo el patrón de bandeo. Solamente en una muestra se observó un producto de amplificación a 900 pb con el primer OPF-10 (Figura 1c), este producto corresponde a la raza 5 de acuerdo con lo previamente reportado por Del Mar Jiménez et al. (2001). 


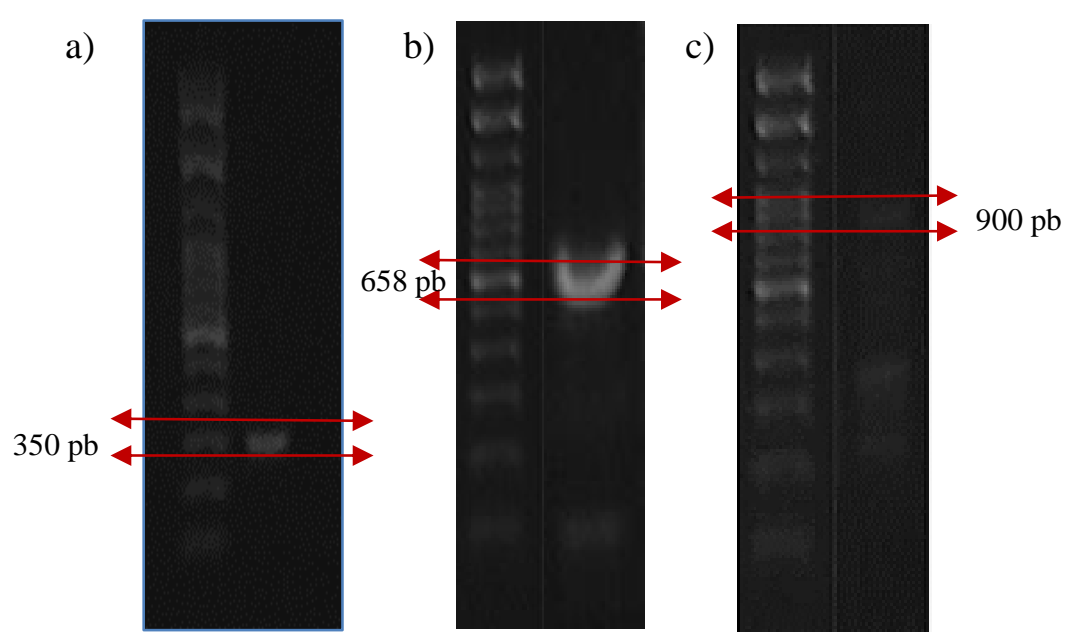

Figura 1. Identificación de los patógenos: a) M. phaseolina (350 pb); b) F. solani (658 pb); y c) $F$. oxysporum f. sp. ciceris $(900 \mathrm{pb})$. Productos de amplificación separados en un gel de agarosa $1 \%$ y teñido con Nucleic acid gel stain (Invitrogen).

Los resultados de otros estudios han demostrado que en el lugar donde se realizaron los aislamientos se han logrado identificar diferentes razas en diferentes áreas de muestreo (ArvayoOrtiz et al., 2011). Por lo tanto, los resultados obtenidos por nuestro equipo de trabajo son consistentes con estos hallazgos.

Actividad antifúngica de extractos vegetales contra $M$. phaseolina por el método de medio envenenado

El efecto de los polifenoles de diferentes fuentes vegetales sobre el crecimiento del hongo $M$. phaseolina se observan en la Figura 2. Como puede apreciarse los polifenoles de L. lucidum y $S$. bicolor mostraron total inhibición sobre el crecimiento micelial del hongo a partir de 300 ppm, mientras que los polifenoles de $M$. oleífera a la misma concentración logro inhibir el $94.5 \%$ del crecimiento micelial. Las $\mathrm{CI}_{50}$ fueron desde $53.65 \mathrm{ppm} \mathrm{M.} \mathrm{oleífera} \mathrm{hasta} 78.09 \mathrm{ppm}$ S. bicolor.

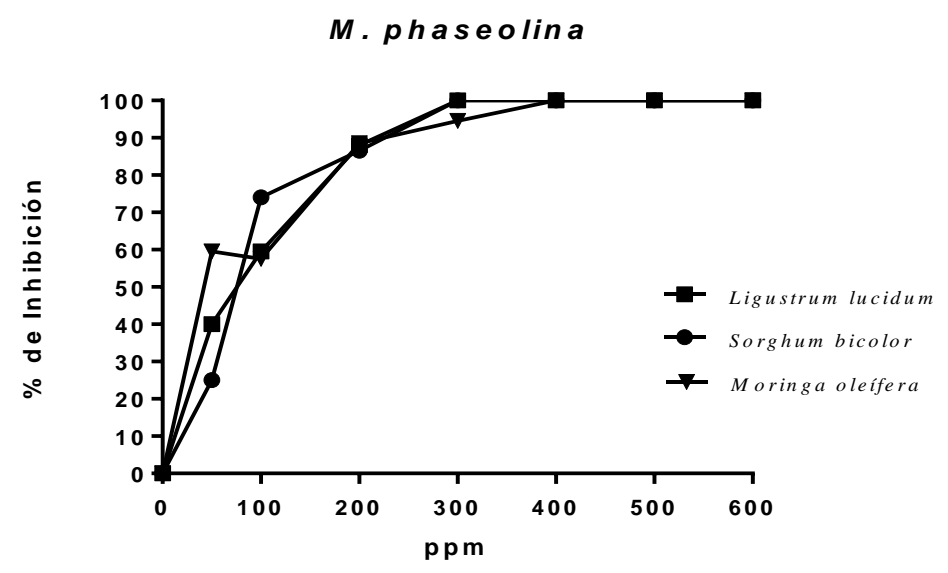

Figura 2. Porcentaje de inhibición de polifenoles obtenidos por extractos etanólicos de fuentes vegetales sobre M. phaseolina. 
Todos los polifenoles mostraron inhibición del crecimiento del hongo, con diferencias significativas respecto al tratamiento control. Los porcentajes de inhibición obtenidos en este trabajo fueron superiores a los reportados por Abreu et al. (2015) quienes en su investigación lograron obtener una inhibición de $60 \%$ utilizando extractos etanólicos de paraíso (Melia azedarach L), moringa (Moringa oleífera) y nim (Azadirachta indica A. Juss) contra Macrophomina phaseolina, mientras que en el presente trabajo se obtuvo una inhibición de 100\%, utilizando polifenoles separados por cromatografía de columna.

Los alcaloides tienen un papel importante en las estrategias defensivas de las plantas frente a patógeno, como la reparación de daños por el sistema antioxidante (Matsuura et al., 2017) y el establecimiento de barreras defensivas de naturaleza bioquímica (Zacarés, 2008). Además, al ser en ocasiones inducidos a través de la ruta de señalización del jasmonato (Matsuura et al., 2017), lo cual explicaría el efecto positivo de los tratamientos en el control de Macrophomina.

La obtención de resultados positivos de este trabajo se asocia a la técnica de obtención de los polifenoles debido a que es una técnica en la cual se muestran buenos rendimientos en cortos periodos y a bajas temperaturas mostrando un proceso de hidratación que favorece la extracción de ciertas sustancias, ya que el ultrasonido hidrata la laminilla (presente en las membranas de células vegetales) y una vez desintegrada la laminilla, las células vegetales quedan expuestas al proceso de extracción del solvente (Toma et al., 2001).

\section{Actividad antifúngica de extractos vegetales contra $F$. oxysporum f. sp. ciceris por el método de microdilución en placa}

La actividad antifúngica de los polifenoles seleccionados de Ligustrum lucidum (hojas), Moringa oleifera (hojas) y Sorghum bicolor (granos) fueron probados contra Fusarium oxysporum f. sp. ciceris (Figura 3). Los resultados mostraron que los tres grupos de polifenoles utilizados inhiben el crecimiento del patógeno entre 60 y $85 \%$ a 1000 ppm. De igual forma, los tres grupos de polifenoles a concentraciones bajas no presentaron inhibición del crecimiento del patógeno, cabe resaltar que los polifenoles de Ligustrum lucidum fueron los que mostraron el porcentaje de inhibición más alto con $83.63 \%$, seguido y con una diferencia mínima del grupo de polifenoles de Moringa oleífera con $82.86 \%$, mientras que Sorghum bicolor solo inhibió $68.3 \%$.

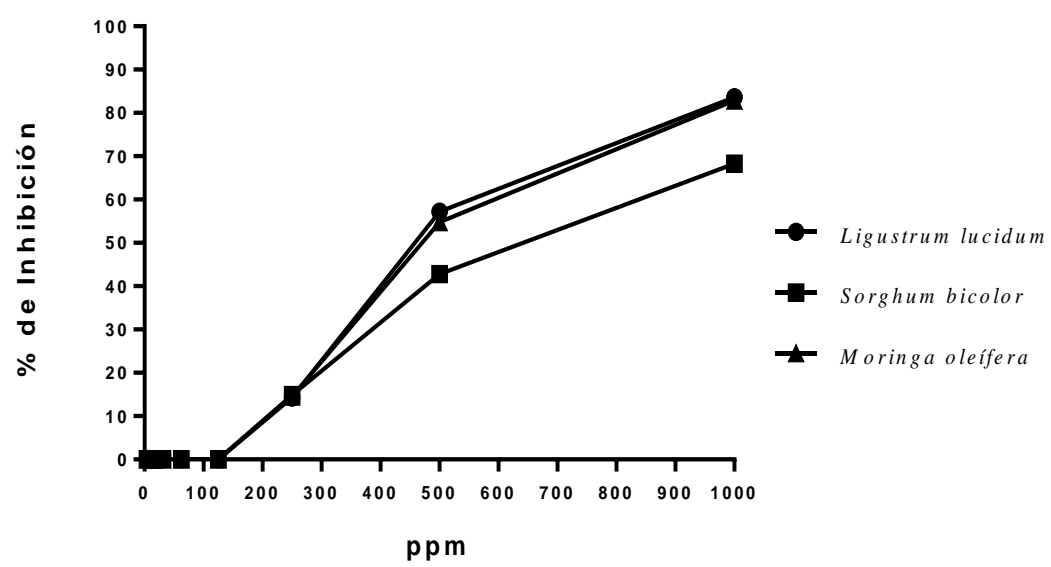

Figura 3. Porcentaje de inhibición de polifenoles de diferentes fuentes vegetales contra Fusarium oxysporum f. sp. Ciceris. 
Los porcentajes de inhibición fúngica obtenidos en el presente estudio usando grupos de polifenoles fueron superiores a los reportados por Dwivedi y Sangeeta (2015), según sus resultados el extracto de Moringa oleífera, Tinospora cardiofolia y Cymbopogon citratus contra Fusarium oxysporum f. sp. ciceris alcanzan una inhibición de $60.29 \%$, de igual forma los resultados reportados por Chandra y Singh (2005) con diferentes extractos de plantas con los cuales solo alcanzó 65\% de inhibición de Fusarium oxysporum f. sp. ciceris. El análisis de varianza mostro diferencias significativas entre la $\mathrm{CI}_{50}$ de los tres grupos de polifenoles siendo aquellos obtenidos de Ligustrum lucidum los que promovieron la $\mathrm{CI}_{50}$ más baja y estadísticamente el mejor de los tres extractos con 492.02 ppm (Cuadro 3).

Cuadro. 3. Concentración inhibitoria al $50 \%\left(\mathbf{C I}_{50}\right)$ de polifenoles obtenidos de diversas fuentes vegetales para la inhibición de Fusarium oxysporum f. sp. ciceris

\begin{tabular}{ccccc}
\hline Fuente vegetal & $\mathrm{CI}_{50}$ & $\mathrm{gl}$ & $\mathrm{F}$ & $p$-valor \\
\hline Sorghum bicolor & $628.82 \mathrm{a}$ & 3 & 82629272.98 & $<0.0001$ \\
Moringa oleifera & $502.22 \mathrm{~b}$ & & & \\
Ligustrum lucidum & $491.99 \mathrm{c}$ & & & \\
\hline
\end{tabular}

$\mathrm{CV}=0.01$. Valores con la misma letra, son estadísticamente iguales (Tukey 0.05); DMS=0.13829.

\section{Actividad antifúngica de polifenoles de diferentes vegetales contra $F$. solani por el método de microdilución en placa}

Se determinó el efecto de los grupos de polifenoles sobre Fusarium solani mediante el porcentaje de inhibición. En el análisis de varianza de la concentración inhibitoria muestra diferencias significativas entre los tratamientos, siendo el extracto de Ligustrum lucidum el que mostro la $\mathrm{CI}_{50}$ más baja (Cuadro 4). Los polifenoles de extractos etanólicos de Ligustrum lucidum, Moringa oleífera y Sorghum bicolor inhibieron $100 \%$ del crecimiento de Fusarium solani en la concentración de 1000 ppm, el resto de las concentraciones siguieron mostrando inhibición siendo las más relevantes los polifenoles de Ligustrum lucidum.

Cuadro. 4. Concentración inhibitoria al $50 \%\left(\mathrm{CI}_{50}\right)$ de polifenoles de diferentes fuentes vegetales para la inhibición de Fusarium solani.

\begin{tabular}{lllll}
\hline Fuente vegetal & CI $_{50}$ & gl & F & p-valor \\
\hline Sorghum bicolor & $94.97 \mathrm{a}$ & 3 & 1574972.8 & $<0.0001$ \\
Moringa oleifera & $78.03 \mathrm{~b}$ & & & \\
Ligustrum lucidum & $54.22 \mathrm{c}$ & & & \\
\hline
\end{tabular}

$\mathrm{CV}=0.08$. Valores con la misma letra, son estadísticamente iguales (Tukey 0.05). DMS=0.12876.

Lo anterior, es relevante si se considera que hay productos químicos que se aplican una o más veces por semana y no logran estos resultados, incluso en condiciones de laboratorio no logran inhibir al $100 \%$ el crecimiento del micelio, tal como lo reportan Yossen y Conles (2016) que, en su trabajo con moléculas comerciales, alcanzan una inhibición de entre 60 y 97\%. Resultados similares al nuestro sobre Fusarium spp. (Figura 4) fueron reportados por Duarte et al. (2013), quienes con aceites esenciales de Piper aduncum subsp. ossanum y Piper aurintum inhiben totalmente el crecimiento de este hongo. Por otra parte, Zaker (2014) concluyó que el extracto etanólico de hojas de Artemisia annua es capaz de inhibir el crecimiento de $F$. solani. 


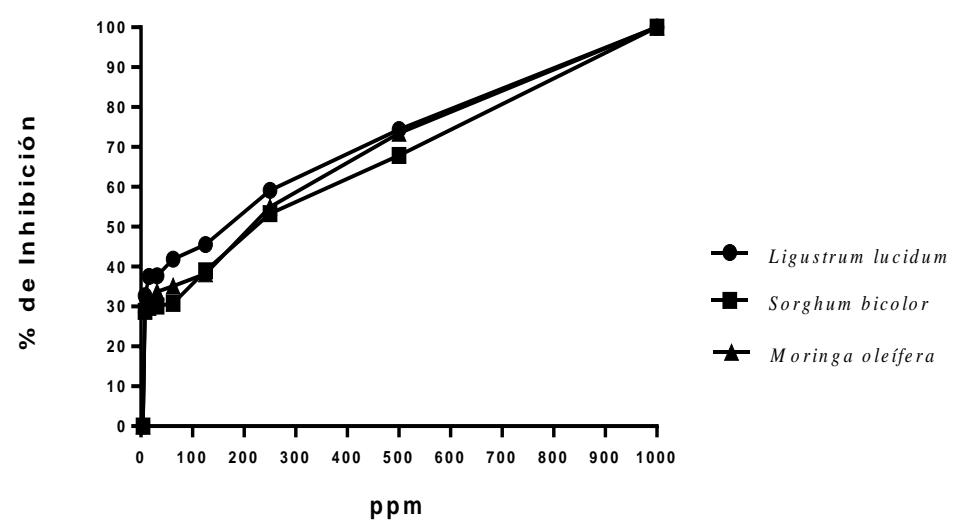

Figura 4. Porcentaje de inhibición de polifenoles de diferentes fuentes vegetales contra $F$. solani.

\section{Conclusiones}

Los polifenoles de trueno (Ligustrum lucidum), moringa (Moringa oleífera) y sorgo (Sorgum bicolor) obtenidos por extracción asistida media ultrasonido-microonda fueron efectivos para inhibir el crecimiento de $M$. phaseolina y $F$. solani al $100 \%$, mientras que para la inhibición de Fusarium oxysporum f.sp. ciceris los polifenoles de Ligustrum lucidum fueron los de mayor efectividad y la concentración inhibitoria ( $\left.\mathrm{CI}_{50}\right)$ más baja $491.99 \mathrm{ppm}$. De igual manera se concluye que los polifenoles de Ligustrum lucidum logran inhibir el crecimiento de los fitopatógenos evaluados, a concentraciones más bajas que las otras fuentes de extracción. Este es el primer reporte de Ligustrum lucidum utilizado para el control de enfermedades de plantas.

\section{Agradecimientos}

Agradecemos al Consejo Nacional de Ciencia y Tecnología (CONACYT)y la Universidad Autónoma Agraria Antonio Narro (UAAAN), por el apoyo financiero para la realización de este trabajo.

\section{Literatura citada}

Arif, M.; Chawla, S.; Zaidi, M. W.; Rayar, J. K.; Variar, M. y Singh. 2012. Desarrollo de cebadores específicos para los géneros Fusarium y $F$. solani utilizando la subunidad de ADNr y el gen del factor de elongación de la transcripción (TEF-1 $\alpha$ ). Rev. Afric. Biotecn. 11(2):444447. https://www.researchgate.net/publication/230555127.

Arvayo, O. R. M.; Esqueda, M.; Acedo F. E.; Sánchez, A. and Gutiérrez, A. 2011. Morphological variability and races of Fusarium oxysporum f. sp. ciceris associated with chickpea (Cicer arietinum) crops. Am. J. Agric. Biol. Sci. 6(1):114-121. https://www.researchgate.net/ publication/280020049.

Ascacio, V. J. A.; Aguilera, C. A. F.; Buenrostro, J. J.; Prado, B. A.; Rodríguez, H. R. and Aguilar, C. N. 2016. The complete biodegradation pathway of ellagitannins by Aspergillus niger in solid-state fermentation. J. Basic Microbiol. 56(4):329-336. doi: 10.1002/jobm.201500557. 
Babu, B. K.; Saxena, A. K.; Srivastava, A. K. and Arora, D. K. 2007. Identification and detection of Macrophomina phaseolina by using species-specific oligonucleotide primers and probe. Mycologia. 99(6):797-803. http://dx.doi.org/10.1080/15572536.2007.11832511.

Basco, M. J.; Bisen, K.; Keswani, C. and Singh, H. B. 2017. Biological management of Fusarium wilt of tomato using biofortified vermicompost. Mycosphere. 8(3):467-483. http://dx.doi.org/10.5943/mycosphere/8/3/8.

Chandra, S.; Choure, K.; Dubey, R. C. and Maheshwari, D. K. 2007. Rhizosphere competent Mesorhizobiumloti MP6 induces root hair curling, inhibits Sclerotinia sclerotiorum and enhances growth of Indian mustard (Brassica campestris). Brazilian J. Microbiol. 38(2):124-130. http://dx.doi.org/10.1590/S1517-83822007000100026.

De-Asmundis, C.; Romero, C. H.; Acevedo, H. A.; Pellerano, R. G. y Vázquez, F. A. 2011. Funcionalización de una resina de intercambio ionico para la preconcentracion de HG (II). Avances en Ciencias e Ingeniería. 2(1):63-70. http://www.redalyc.org/articulo.oa?id= 323627681006.

Duarte, Y.; Pino, O. y Martínez, B. 2013. Efecto de cuatro aceites esenciales sobre Fusarium spp. Rev. Protec. Veget. 28(3):232-235. http://scielo.sld:cu/scielo.php?script=sci_arttext\&pid= $\mathrm{S}=1010-27522013000300013$.

Dwivedi, S. K. 2015. Eficacy of some medical plant extract against Fusarium oxysporum f. sp. ciceri causing chickpen wilt. Asian J. Crop Sci. 7(2):138-146. doi:10.3923/ajcs.2015. 138.146.

Gabrielson, J.; Hart, M.; Jarelöv, A.; Kühn, I.; McKenzie, D. and Möllby, R. 2002. Evaluation of redox indicators and the use of digital scanners and spectrophotometer for quantification of microbial growth in microplates. J. Microbiol. Methods. 50(1):63-73. http//dx.doi.org/10.1016/S0167-7012(02)00011-8.

Gakuya, D. W.; Itoga, S. M.; Mbaria, J. M.; Muthee, J. K. and Musau, J. K. 2013. Ethnobotanical survey of biopesticides and other medicinal plants traditionally used in meru central district of Kenya. J. Ethnopharmacol. 145(2):547-553. Doi: 10.1016/j.jep.2012.11.028.

Jasso-Rodríguez, D.; García, R. R.; Castillo, H. F.; González, C. A.; Galindo, A. S.; Quintanilla, J. V. and Zuccolotto, L. M. 2011. In vitro antifungal activity of extracts of Mexican Chihuahuan desert plants against postharvest fruit fungi. Industrial Crops and Products. 34(1):960-966. https://doi.org/10.1016/j.indcrop.2011.03.001.

Jiménez, G. M. M.; Pérez, A. E. and Jiménez, D. R. M. 2001. Identification of pathogenic races 0, 1B/C, 5, and 6 of Fusarium oxysporum f. sp. ciceris with random amplified polymorphic DNA (RAPD). Eur. J. Plant Pathol. 107(2):237-248. doi: 10.1023/a: 1011294204630.

Landa, B. B.; Navas, C. J. A.; Jiménez, G. M. M.; Katan, J.; Retig, B. and Jiménez D. R. M. 2006. Temperature response of chickpea cultivars to races of Fusarium oxysporum f. sp. ciceris, causal agent of Fusarium wilt. Plant Dis. 90(3):365-374. http://dx.doi.org/10.1094/PD-900365.

Masoko, P.; Picard, J. and Eloff, J. N. 2005. Antifungal activities of six South African Terminalia species (Combretaceae). J. Ethnopharmacol. 99(2):301-308. http://dx.doi.org/10.1016/ j.jep.2005.01.061.

Matsuura, H. N. and Fett, N. A. G. 2017. Plant alkaloids: main features, toxicity, and mechanisms of action. Plant toxins Gopalakrishnakone, P.; Carlini, C. R. and Igabue, B. R. (Ed.). 243261p. doi 10.1007/978-94-007-6728-7_2-1, 2015.

Morales, G. J. A. y Durón, N. L. J. 2004. Aspectos generales. Morales, G. J. A.; Durón, N. L. J.; Martínez, D. G.; Núñez, M. D. J. H. y Fu, C. A. A. (Ed.). El cultivo de garbanzo blanco en Sonora. Libro Técnico Núm. 6. INIFAP-Campo Experimental Costa de Hermosillo, Sonora, México. 11-24 pp. 
Moreno, L. S.; González, S. L. N.; Salcedo, M. S. M.; Cárdenas, Á. M. L. y Perales, R. A. 2011. Efecto antifúngico de extractos de gobernadora (Larrea tridentata L.) sobre la inhibición in vitro de Aspergillus flavus y Penicillium sp. Polibotánica. 32:193-205. http://www.redalyc.org/articulo.oa?id=62119933012.

Navas, C. J. A.; Hau, B. and Jiménez-Díaz, R. M. 1998. Effect of sowing date, host cultivar, and race of Fusarium oxysporum f. sp. ciceris on development of Fusarium wilt of chickpea. Phytopathology. 88(12):1338-1346.

Paredes, E. J. E.; Carrillo, F. J. A.; García, E. R. S.; Allende, M. R.; Sañudo, B. J. A. y Valdez, T. J. B. 2009. Microorganismos antagonistas para el control del complejo de hongos causantes de la rabia del garbanzo (Cicer arietinum L.) en el Estado de Sinaloa, México. Rev. Mex. Fitopat. 27(1):27-35.

Sharma, K. D. and Muehlbauer, F. J. 2007. Fusarium wilt of chickpea: physiological specialization, genetics of resistence and resistence gene tagging. Euphytica. 157(1):1-14. doi: http://dx.doi.org/10.1007/s10681-007-9401-y.

Sparks, T. C.; Hahn, D. R. and Garizi, N.V. 2017. Natural products, their derivatives, mimics and synthetic equivalents: role in agrochemical discovery. Pest Manag. Sci. 73(4):700-715. Doi: $10.1002 / p s .4458$.

Sánchez, S. M.; Gambardella, J. L. and Enriquez, I. D. 2013. First report of crown rot of strawberry caused by Macrophomina phaseolina in Chile. Plant Dis. 97-996 p. http://dx.doi.org /10.1094/PDIS-12-12-1121-PDN.

SIAP. 2017. Sistema de Información Agroalimentaria y Pesquera. Avance de siembras y cosechas, resumen nacional por cultivo. https://www.gob.mx/siap/.

Toma, M.; Vinatoru, M.; Paniwnyk, L. and Mason, T. 2001. Investigation of the effects of ultrasound on vegetals tissues during solvent extraction. Ultrasonics Sonochemistry. 8(2):137-142. http://dx.doi.org/10.1016/S1350-4177 (00)00033-X.

Yossen, V. E. y Conles, M. Y. 2016. Eficacia de fungicidas in vitro para el control de Fusarium oxysporum y $F$. proliferatum, agentes causales de marchitamiento en el cultivo de orégano en la Argentina. Rev. Industrial y Agrícola de Tucumán. 91(1):19-25. https://riat.eeaoc. org.ar/ojs/ index.php /riat/ article/view/v91n1a03/33.

Zacarés, L. 2008. Nuevas aportaciones al metabolismo secundario del tomate, identificación y estudio de moléculas implicadas en la respuesta a la infección con Pseudomonas syringae pv. Tomato. Tesis Doctoral. Universidad Politécnica de Valencia. https://doi.org/10.4995/ Thesis/10251/3021, es.

Zaker, M. 2014. Antifungal evaluation of some plant extracts in controlling Fusarium solani, the causal agent of potato dry rot in vitro and in vivo. Inter. J. Agri. Biosci. 3(4):190-195. www.ijagbio.com.

Zhang, J. Q.; Zhu, Z. D.; Duan, Z. D.; Wang, C. X. and Li, H. J. 2011. First report of charcoal rot caused by Macrophomina phaseolina on mungbean in china. Plant Dis. 95(7):95-87. http://dx.doi.org/10.1094/PDIS-01-11-0010. 